\title{
The problem of estimating the sustainable development of the integrated technogenic industrial system
}

\author{
Sultan Ramazanov ${ }^{1, *}$ and Oleksandr Honcharenko ${ }^{1, * *}$ \\ ${ }^{1}$ Economics Information Systems Department, Kyiv National Economic University named after Vadym Hetman, 54/1 Peremohy Ave., \\ Kyiv, 03057, Ukraine
}

\begin{abstract}
The purpose of this work is to research the problem of sustainability of the integrated technogenic system in an innovative economy and "Industry 4.0". The paper deals with the methods of assessing the level of sustainable development of the integrated technogenic system as a family of models for eco-economic and socio-humanitarian management of technogenic economic objects. The economic approach to modeling a sustainable development is considered, which consists of the optimal use of limited resources and applies natural, energy and resource-saving technologies to generate aggregate income. At the same time, the transition to the information society leads to a change in the structure of aggregate capital in favor of human, increasing intangible flows, flows of information and intellectual property. The problem of sustainable development through 7 main assets (capitals) that support the viability of socioenvironmental and economic systems is considered. The concept of sustainable development, the system of global dimensions of sustainable development and the level of sustainable development are defined. The presented methodology for the formation of humanitarian component of technogenic regional production uses available statistic data. Application of these methods will improve efficiency of managerial decisions in the technogenic regional production management, maximize benefits from the use of innovations and define strategic innovative directions for regional development.
\end{abstract}

\section{Introduction: problem analysis and statement}

The global goal of this research is to create a methodology for making managerial decisions for sustainable, safe, secure and viable development of environmental economy and integrated technogenic systems and objects.

The concept of sustainable and safe development of the state and individual regions allows to ensure stable and balanced development of four sectors: economic, ecological, social and spiritual and moral unity on the basis of innovative socio-humanitarian technologies, combining the principles of economic efficiency, social security and environmental safety.

Currently, the issues of ecological, economic and socio-humanitarian safe and sustainable development of civilization have come to the forefront of scientific research and public consciousness in general. Mankind has reached the point where modern civilization, often called technogenic-consumer, has found its hopelessness, when it is necessary to seriously reconsider its basis and consciously choose another, spiritual and ecological, development strategy, otherwise humanity may be destroyed from Earth due to global systemic crises that have erupted in recent years. To solve this problem, humanity needs to abandon a number of stereotypes and direct the vector of civilizational development to the formation of the

\footnotetext{
*e-mail: sramazanov@i.ua

**e-mail: alexgontcharenko@gmail.com
}

sphere of mind ("noosphere" according to V.I. Vernadsky). The formation of the noosphere-ecological imperative is associated with the formation of a society that is able to ensure the coevolutionary and viable development of civilization for planetary integrity. Sustainable and safe development is impossible without the spiritual, cultural and educational improvement of man himself. The new model of civilizational development, which implements non-traditional ecological, economic and demographic imperatives, must have a deeply humanistic social orientation. Such an approach to understanding the noosphere requires the creation of a new model of science, which should be based not only on a rational intellectual approach to the ecosystem, but also based on its spiritual and cultural components. At the same time, the most important problem is the integration of science, education and innovative technology based on the noosphere paradigm of sustainable development.

The problem of studying the sustainable and safe development of the state and individual regions in socioenvironmental and economic systems with humanitarian components, i.e. on the basis of integration of 4 spheres of activity and functioning of modern complex systems in innovative economy (presented both in phase space and in ESTI space - "education - science - technology - innovation"), as well as in modern science in general, is the main and relevant. Only the integration of methods of modeling socio-economic, ecological, cultural, spiritual and other 
processes can ensure the sustainability and viability of the entire system [1-7].

Also, note that a system-thinking and active person usually forecasts and considers his/her performance results, compares his/her capabilities, considers environmental interests, those of future generations and the need for noospheric development.

The purpose of the paper is to study the problem of sustainability of integrated technogenic system in an innovative economy and to research the methods and methodologies for assessing the level of sustainable development of the state and individual regions in order to ensure stable and balanced development of four sectors: economic, ecological, social and spiritual and moral unity on the basis of innovative sociohumanitarian technologies, combining into a holistic system the principles of economic efficiency, social security and environmental security.

Description of key findings. Carrying out a comprehensive analysis of the sustainability of regional development involves the use of criteria and indicators that allow to obtain a reliable assessment of its level, direction and intensity of change. However, economics has not finally developed approaches to justify their choice, methods of calculation, determination of patterns of development, etc. The main disadvantage of the existing methodological provisions is that they do not allow to fully assess the sustainability of the region, the degree of influence of various factors on the level of its change and discrepancies with the limit values. Different views among scholars dealing with the problem of sustainable development of the region are manifested in the choice of criteria that should be the basis for assessing the sustainability of development.

We note that the general scheme of integration model of steady safe ecological, economic, social and humanitarian development of system is presented in [1-3, 6-8].

The paradigm of sustainable development, which provides a dynamic process of successive positive changes that ensure the balance of economic, social and environmental aspects, should be the basis for the formation of approaches to solving the problems of territorial entities. This is especially relevant today, when the focus of economic reforms is shifting to the level of regions and strengthening their role in the implementation of economic policy. The priority approach in the implementation of reforms at the regional level should be the belief that the development of the territory should not be equated with its economic development. It is impossible to consider the region developing steadily only on the basis of increase of economic indicators. Sustainable development should be aimed at achieving a high quality of life, with a positive dynamic of indicators. The priority of the new stage of economic change is the innovative modernization of the regional economy.

It is believed that the term "sustainable development" is inherently innovative, because for the continuous, stable operation of any system in changing environmental conditions, it must constantly increase the degree of organization, adapting to these changes, i.e. generate new forms and mechanisms of stability support.
The transition to sustainable development requires radical transformations, at the center of which is the socialization, greening and humanization of all major human activities, changing his consciousness and creating a new "sustainable society". Such changes must take place purposefully, consciously, taking into account socio-economic, political, technical and other conditions. In general, the level of sustainable development of the technogenic region is due to the interaction of factors' groups of socioeconomic, environmental and innovative nature.

Socio-economic factors include: production and resource potential (labor, material, financial, raw materials, fixed capital, etc.), market (factors of demand, supply and distribution; interpenetration of regional, national and world markets), strengthening the social function of the state, income level (propensity to consume, save, invest), education and health care, social protection, level and quality of life, level of environmental awareness.

The environmental aspect of sustainable development implies the rational use of natural resources (subsoil, extraction of natural resources, forest, water, land fertility, wildlife) on the principles of their economy, efficiency of recreational capacity and investment in environmental activities. This approach to sustainability means the maximum reduction of their use, the search for substitutes, the widespread introduction of resource-saving technologies.

Innovative factors include intellectual potential (ideas and knowledge, which turn into new sources of raw materials and power; information), scientific and technical potential (substitution technologies, technological activity), investment in innovation.

Thus, sustainable development means that the socioeconomic system ensures the dynamic stability of its properties, applying at the same time the whole set of factors that affect the level of competitiveness of the region's economy.

The system of indicators that characterize the sustainable development of the technogenic region can be identified as criteria for assessing the above factors. Leading international organizations are elaborating indicators of sustainable development: United Nations, World Bank, Organization of Economic Cooperation and Development (OECD), European Commission, Scientific Committee on Problems of the Environment (SCOPE) and others. Among individual countries, the experience, scale, duration and complexity of a system of sustainable development indicators in the United States and the United Kingdom should be particularly noted. These countries began this work at the governmental level in the mid-1990s.

\section{Main results}

The problem of sustainable development on the basis of the "hexagon" of fixed assets, which support the activity of SEESM [1]. The main assets that support the viability of integrated SEESM are the following 7 factors: $S-$ Social capital; $\Phi$ - Financial capital; $N$ - Natural capital (land, water, etc.); $K$ - Physical capital (fixed assets); $L$ - Labor resources; $H$ - Human (intellectual) capital; $I$ Institutional factor (resource). 
The generalized production-technological function (PTF) can be represented in general as a nonlinear function:

$$
Y(t)=F[K(t, L(t), H(t), N(t), \Phi(t), S(t), I(t) ; \vec{c}] .
$$

It can be used to analyze the sustainable development.

The level of sustainable development (SDL) will be assessed using the index $I_{s d l}$, which is calculated as the sum of indices for four areas: economic $\left(I_{\text {eco }}\right)$, ecological $\left(I_{e c l}\right)$, social $\left(I_{s o c}\right)$ and humanitarian $\left(I_{h u m}\right)$ with the appropriate weight coefficients, that is:

$$
\begin{gathered}
I_{s d l}=\alpha_{1} I_{e c o}+\alpha_{2} I_{e c l}+\alpha_{3} I_{s o c}+\alpha_{4} I_{h u m}, \\
\alpha_{1}+\alpha_{2}+\alpha_{3}+\alpha_{4}=1, \alpha_{i} \geq 0, i=1, \ldots 4
\end{gathered}
$$

Each of the indices $I_{e c o}, I_{e c l}, I_{s o c}$ and $I_{h u m}$ is calculated using well-known in international practice indices and indicators.

Using the arithmetic mean form of construction of the generalized indicator at decrease of social and economic indicators and at increase of ecological ones, the leveling of a threatening situation is possible. Therefore, the content of the considered indicator is more consistent with the geometric mean value, which reflects the proportionality between the indicators. In addition, the considered indicators will reflect the real situation in the region. The level of sustainable development of the region can be calculated by the following formula:

$$
I_{s d l}=\sqrt[4]{\left[\alpha_{1} I_{e c o} \times \alpha_{2} I_{e c l} \times \alpha_{3} I_{s o c} \times \alpha_{4} I_{h u m}\right]} .
$$

In particular, the level of sustainability of economic development of the region can be determined by the following formula:

$$
I_{e c o}=\sqrt[5]{I_{n} \times I_{u} \times I_{\Phi} \times I_{m} \times I_{n p}},
$$

where $I_{\text {eco }}$ - the level of sustainability of economic development of the region; $I_{n}$ - level of production component of regional development: innovation, labor, financial and natural resources; $I_{u}$ - the level of innovation component of regional development; $I_{\Phi}-$ the level of the financial component of regional development; $I_{m}$ - the level of the labor component of regional development; $I_{n p}$ - the level of natural resource component of regional development.

This construction of the indicator will reflect the importance of each of the considered components: ecoeconomic and socio-humanitarian subsystems (spheres) in the performance of the objective function. A change in any of the private indicators leads to a change in the value of the aggregate indicator and captures a change in the steady state of the region. In the general case, all indicators change over time, i.e. have a certain dynamics.

Simple conditions for sustainable development (SD) are defined as follows:

1) condition of weak stability:

$$
\frac{d F[\cdot]}{d t} \geq 0 \quad \text { or } \quad F_{t+1}[\cdot] \geq F_{t}[\cdot]
$$

where $F_{t}[\cdot]=F[K(t), L(t), H(t), N(t), \Phi(t), S(t), I(t), \vec{c}]$.
2) condition of strong stability:

$$
\frac{d F[\cdot]}{d t} \geq 0, N=N^{C}+N^{S} \text { and } \frac{d N^{C}}{d t} \geq 0 \text {, or } N_{t+1}^{C} \geq N_{t}^{C},
$$

where $N^{C}$ - critical part of natural capital, and $N^{S}-$ natural capital, which can be replaced by artificial.

For example, given critical natural capital $N^{C}$, sustainable development can be supplemented by a time limit on depletion of this value. For a time-decreasing production function, the arguments of which are aggregated variables: labor $-L$, capital $-K$ and natural resource $N$, we will have the ratio:

$$
F_{t}(K, L, N) \leq F_{t+1}(K, L, N)
$$

or, in the general case:

$$
\begin{array}{r}
F(K(t), L(t), H(t), N(t), \Phi(t), S(t), I(t), \vec{c}) \leq \\
\leq F(K(t+1), L(t+1), H(t+1), N(t+1), \\
\Phi(t+1), S(t+1), I(t+1), \vec{c})
\end{array}
$$

And it also requires compliance with the condition of not decreasing in time the value of $N^{C}$, i.e. $N_{t}=N_{t}^{C}+N_{t}^{S}$, as well as the condition of partial replacement of natural capital $N$ by artificial $N^{S}$ (or non-renewable resource for renewable resource): $N_{t}=N_{t}^{C}+N_{t}^{S}$.

The integrated level of sustainable development for all capital (resources) can be defined, for example, in the case of linear dependence as:

$$
\begin{aligned}
& Y_{s d l}(t)=c_{1} K(t)+c_{2} L(t)+c_{3} H(t)+ \\
& +c_{4} N(t)+c_{5} \Phi(t)+c_{6} S(t)+c_{7} I(t),
\end{aligned}
$$

where $c_{1}, c_{2}, c_{3}, c_{4}, c_{5}, c_{6}, c_{7}$ weight (normalizing and scaling) coefficients.

In the general case, the integral level of sustainable development can be represented as a nonlinear function:

$$
\left.Y_{s d l}(t)=F_{s d l}[] K(t), L(t), H(t), N(t), \Phi(t), S(t), I(t), \vec{c}\right] .
$$

Private versions of the PTF model:

a) Mankiw-Romer-Weil model. Option of accounting for human capital $H$ in the production function (PF), along with physical capital $(K)$, labor $(L)$ and natural $(N)$ resources:

$$
Y(t)=K^{\alpha}(t) \cdot H^{\beta}(t) \cdot[A(t) \cdot L(t)]^{1-\alpha-\beta},
$$

where $\alpha, \beta>0, \alpha+\beta<1 ; H ; A(t)-$ function of scientific and technological progress. Note that $\alpha$ is a part of capital provided by investment growth (capital costs); $\beta$ is similar.

b) Model of accounting for all fixed assets:

$$
Y(t)=A(t) K^{\alpha}(t) \cdot L^{\beta}(t) \cdot H^{\gamma}(t) \cdot S^{\rho}(t) \cdot \Phi^{q}(t) \cdot N^{\tau}(t) \cdot I^{v}(t),
$$

where $\alpha, \beta, \gamma, \rho, q, \tau, v>0$ and $\alpha+\beta+\gamma+\rho+q+\tau+v=1$.

The following notations are also used here: $K$ - physical capital, $L$ - labor, $H$ - human capital, $S$ - social capital, $\Phi$ - financial capital, $N$ - natural resources (land, water, etc.), $A(t)$ is a function of the level of scientific, technical and technological development, for example, $A(t)=$ 
$a T^{S}(t)$, where $T(t)$ - volume of innovative technologies (resources).

The system of global measurements of sustainable development. An important problem in implementing the concept of sustainable development is the formation of a system of measurements (indices and indicators) for quantitative and qualitative assessment of this complex process. The main requirements for this system of measurements are its completeness of information and the adequacy of the presentation of the interconnected triad of components of sustainable development. Well-known international organizations and numerous scientific teams are currently working in this direction, but unambiguous coordination of this system of measurements has not been achieved yet.

Here is a system of measurements of sustainable development, proposed by the Institute for Applied System Analysis of Igor Sikorsky Kyiv Polytechnic Institute [2, 9].

The level of sustainable development is assessed using the corresponding $I_{s d l}$ index, which is calculated as the sum of indices for four areas: economic $\left(I_{\text {eco }}\right)$, ecological $\left(I_{e c l}\right)$, social $\left(I_{s o c}\right)$ and humanitarian $\left(I_{h u m}\right)$ with the appropriate weight coefficients.

Of course, all indicators that affect the components of these indices, as well as these indices themselves, are measured in different units and have different interpretations. Therefore, they are reduced to a normalized form so that their changes, as well as changes in the indices themselves, were in the range from 0 to 1 . In this case, the worst values of these indicators will correspond to numerical values close to 0 , and the best - will bring these values closer to 1 . This rationing allows you to calculate each of the indices $I_{e c o}, I_{e c l}, I_{s o c}$ and $I_{\text {hum }}$ in the form of the average sum of its components with the appropriate weight coefficients.

1. The index of economic area $\left(I_{\text {eco }}\right)$ is formed from two global indices:

a) the index of competitive development (the index of competitiveness $-I_{c}$ ), developed by the organizers of the World Economic Forum. This index is calculated annually for 117 economies of the world and is published in the form of the so-called "Global Competitiveness Report". The competitiveness index is formed from the following three indicators: the indicator of technological development of the country; indicator of civil institutions and indicator of macroeconomic environment. These three indicators are calculated based on the use of 47 data sets of the state of technology and innovation development, the level of information and communication technology, the level of $R \& D$ spending, the level of foreign investment, the level of business independence from government, the level of corruption in the country, etc.;

b) index of economic freedom $\left(I_{e f}\right)$, which was developed by the intellectual center of the Heritage Foundation. It is published annually in the Wall Street Journal. The index of economic freedom is formed from the following ten indicators: the country's trade policy; fiscal burden from the government; government intervention in the economy; monetary policy; capital flows and foreign investment; banking and financial activities; pricing and remuneration policies; private property rights; regulatory policies; informal market activity. These ten indicators are calculated based on the use of 50 sets of various economic, financial, legislative and administrative data.

2. The index of ecological area $\left(I_{e c l}\right)$ is assessed using the well-known ESI (Environmental Sustainability Index), calculated by the Center for Environmental Law and Policy at Yale University (USA) for 146 countries. The ESI index is formed of 21 environmental indicators, which were calculated based on the use of 76 sets of environmental data on the state of natural resources in the country, the level of environmental pollution in the past and today, the country's efforts to manage environmental conditions characteristics and more.

The ESI index quantifies a country's ability to protect its environment, both in the current period and in the long run, based on the following five criteria: the existence of a national environmental system; possibility to counteract environmental influences; reducing people's dependence on environmental influences; the country's social and institutional capacity to respond to environmental challenges; the possibility of global control over the environmental state of the country. In addition, this index can be used as a powerful tool for decision-making on an analytical basis, taking into account the social and economic areas of sustainable development.

3. The index of the social area $\left(I_{s o c}\right)$ is formed by averaging three global indices:

a) Index of Quality and Safety of Life $\left(I_{q}\right)$, developed by the international organization Economist Intelligence Unit. This index is formed using the following nine indicators: GDP per capita at purchasing power parity; average life expectancy of the population; rating of political stability and security of the country; the number of divorced families per 1,000 population; level of public activity (activity of trade unions, public organizations, etc.); differences in latitude between warmer and colder regions of the country; unemployment rate in the country; the level of political and civil liberties in the country; the ratio between the average wages of men and women.

b) Human Development Index $\left(I_{h d}\right)$, used by the United Nations Development Program. It is formed with the help of the following three indicators: the average life expectancy of the country's population; level of education and standard of living of the country's population, measured by GDP per capita at purchasing power parity (GDP per capita).

c) Index of a knowledge-based society, or K-society $\left(I_{k s}\right)$, developed by the United Nations Department of Economic and Social Development. This index is determined by three main indicators: intellectual assets of society; development prospects of society and development quality of society, which are formed by 15 data sets on the level of youth education and information, investment climate in the country, corruption, inequality of material and social benefits (GINI-index), the level of child mortality, etc.

4. Methods of forming the humanitarian index $\left(I D X^{H U M}\right.$ or $I_{\text {hum }}$ ) [10] An urgent problem is the formation of a methodology for calculating the humanitarian index, which has an available statistical basis and, along with other indices, can be used in modeling and to assess the level of sustainable development of regions. There- 
fore, the task is to develop a methodology for forming a humanitarian index to assess the level of sustainable development of the region. The basis for the formation of the humanitarian index is directly the input data, which in some way is aggregated into parameters. The parameters are aggregated into indicators, and the indicators already make up the humanitarian index.

The information base for the formation of the humanitarian index was the data of the State Statistics Service of Ukraine for the period from 2000 to 2014. 87 items of input data were selected, which were aggregated into 22 parameters. The parameters were aggregated into 10 indicators, and the indicators were aggregated into one humanitarian index.

In order to be able to compare regions without being too subjective, the values of all input data were calculated per capita of the permanent population of a particular region for a particular year.

Input standardization was performed, after which the "worst" value of the input data corresponded to the value " 0 ", and the "best" - the value " 1 ". When the "best" value of the input data corresponds to their largest value, standardization is carried out according to the formula:

$$
\begin{gathered}
I D_{i}^{S T}\left(R E G_{j} Y R_{k}\right)=\frac{I D_{i}^{O R}\left(R E G_{j} Y R_{k}\right)}{\max _{R E G_{j}}\left(I D_{i}^{O R}\left(R E G_{j} Y R_{k}\right)\right)}, \\
i=1 \ldots 87, j=1 \ldots 27, k=2000 \ldots 2014,
\end{gathered}
$$

where $I D^{S T}$ - standardized input data values, $I D^{O R}$ - original input data values, $R E G$ - region, $Y R$ - year. In the case when the best values of input data correspond to their smallest values, standardization is carried out according to the formula:

$$
\begin{gathered}
I D_{i}^{S T}\left(R E G_{j} Y R_{k}\right)=1-\frac{I D_{i}^{O R}\left(R E G_{j} Y R_{k}\right)}{\max _{R E G_{j}}\left(I D_{i}^{O R}\left(R E G_{j} Y R_{k}\right)\right)}, \\
i=1 \ldots 87, j=1 \ldots 27, k=2000 \ldots 2014
\end{gathered}
$$

where $I D^{S T}$ - standardized input data values, $I D^{O R}$ - original input data values, $R E G$ - region, $Y R$ - year.

"Preliminary" weight coefficients were calculated for the input data $W C^{P R}\left(I D_{j}^{S T}\left(R E G_{j}\right)\right)$ using the principal component method. The "preliminary" weight coefficients were reduced to a single value by the mean formula:

$$
\begin{gathered}
W C\left(I D_{i}^{S T}\right)=1 / 27 \sum_{j} W C^{P R}\left(I D_{j}^{S T}\left(R E G_{j}\right)\right) \\
i=1 \ldots 87, j=1 \ldots 27
\end{gathered}
$$

where $W C$ - input data weight coefficients, $W C^{P R}$ - "preliminary" weight coefficients of input data, $I D^{S T}$ - standardized input data values, $R E G$ - region. The sum of the input data weight coefficients for each parameter is always equal to one.

Regarding the calculation of parameter values, the parameter value is equal to the sum of the values of all input data included in it, multiplied by the corresponding weight coefficients.
For example:

$$
\begin{aligned}
& P R M_{1}\left(R E G_{j}, Y R_{k}\right)=\sum_{i=1}^{3} I D_{i}^{S T}\left(R E G_{j} Y R_{k}\right) \cdot W C\left(I D_{i}^{S T}\right), \\
& P R M_{4}\left(R E G_{j}, Y R_{k}\right)=\sum_{i=9}^{18} I D_{i}^{S T}\left(R E G_{j} Y R_{k}\right) \cdot W C\left(I D_{i}^{S T}\right), \\
& P R M_{12}\left(R E G_{j}, Y R_{k}\right)=\sum_{i=40}^{44} I D_{i}^{S T}\left(R E G_{j} Y R_{k}\right) \cdot W C\left(I D_{i}^{S T}\right), \\
& j=1 \ldots 27, k=2000 \ldots 2014,
\end{aligned}
$$

where $P R M$ - parameter, $I D^{S T}$ - the standardized values of the input data, $W C$ - the weight coefficients of the input data, $R E G$ - region, $Y R$ - year.

A total of 22 parameters are used. As with the input data, "preliminary" weight coefficients $W C^{P R}\left(P R M_{i}\left(R E G_{j}\right)\right)$ were calculated for the parameters using the principal component method. The "preliminary" weight coefficients were also reduced to a single value by the mean formula:

$$
\begin{gathered}
W C\left(P R M_{j}\right)=1 / 27 \sum_{j} W C^{P R}\left(P R M_{i}\left(R E G_{j}\right)\right), \\
i=1 \ldots 22, j=1 \ldots 27,
\end{gathered}
$$

where $W C$ - weight coefficient of the parameter, $W C^{P R}$ - the "preliminary" weight coefficient of the parameter, $P R M$ - parameter, REG - region. The sum of the weight coefficients of the parameters for each indicator is always equal to one.

The values of the indicator are the values of the parameters included in it, multiplied by the corresponding weight coefficients. Here are some of the formulas:

$$
\begin{aligned}
I D T_{1}\left(R E G_{j}, Y R_{k}\right) & =\sum_{i=1}^{3} P R M_{i}\left(R E G_{j}, Y R_{k}\right) \cdot W C\left(P R M_{i}\right), \\
I D T_{4}\left(R E G_{j}, Y R_{k}\right) & =\sum_{i=10}^{14} P R M_{i}\left(R E G_{j}, Y R_{k}\right) \cdot W C\left(P R M_{i}\right), \\
I D T_{10}\left(R E G_{j}, Y R_{k}\right) & =\sum_{i=21}^{22} P R M_{i}\left(R E G_{j}, Y R_{k}\right) \cdot W C\left(P R M_{i}\right), \\
j= & 1 \ldots 27, k=2000 \ldots 2014,
\end{aligned}
$$

where $W C$ - the weight coefficient of the indicator, $W C^{P R}$ - the "preliminary" weight coefficient of the parameter, $I D T$ - indicator, $R E G$ - region, $Y R$ - year.

For the indicators, "preliminary" $W C^{P R}\left(I D T_{i}\left(R E G_{j}\right)\right)$ weight coefficients were calculated using the principal component method. The "preliminary" weight coefficients were reduced to a single value using the average value formula:

$$
\begin{gathered}
W C\left(I D T_{i}\right)=1 / 27 \sum_{j} W C^{P R}\left(I D T_{j}\left(R E G_{j}\right)\right) \\
j=1 \ldots 10, j=1 \ldots 27
\end{gathered}
$$


where $W C$ - the weight coefficient of the indicator, $W C^{P R}$ - the "preliminary" weight coefficient of the indicator, $I D T$ - indicator, REG - region. The sum of the weight coefficients of the indicators that make up the humanitarian index is always equal to one.

The value of the humanitarian index is equal to the sum of the values of all indicators included in it, multiplied by the corresponding weight coefficients, and is calculated by the formula:

$$
I D X^{H U M}\left(R E G_{j}, Y R_{k}\right)=\sum_{i=1}^{10} I D T_{i}\left(R E G_{j} Y R_{k}\right) \cdot W C\left(I D T_{i}\right),
$$

$$
j=1 \ldots 27, k=2000 \ldots 2014,
$$

where $I D X^{H U M}$ - humanitarian index, IDT - indicator, $W C$ - weight coefficient of the indicator, $R E G$ - region, $Y R$ - year. The values of humanitarian indices $I D X^{H} U M$ were calculated for the period from 2000 to 2014 for the regions of Ukraine.

\section{Conclusion}

The integration model of sustainable development is shown as a family of models for the creation of integrated information systems of ecological, economic and sociohumanitarian management of various socio-organizational systems and especially economic objects of technogenic nature to ensure sustainable and viable development. The economic approach to modeling sustainable development is considered, which consists of the optimal use of limited resources and applies natural, energy and resource-saving technologies to generate aggregate income. At the same time, the transition to the information society leads to a change in the structure of aggregate capital in favor of human, increasing intangible flows, flows of information and intellectual property.

The problem of sustainable development through 7 main assets that support the viability of socioenvironmental and economic systems is considered. The concept of sustainable development, the system of global measurements of sustainable development and the level of sustainable development are defined.
The method of formation of the humanitarian component with the use of available statistics, which is described by the humanitarian index and is included in the models of quality condition indices (IQC), is presented. The use of these methods will increase the efficiency of solutions in the management of technogenic regional production, will increase the efficiency of the use of innovations and will identify areas of innovation strategies of the regions.

\section{References}

[1] S. Ramazanov, O. Honcharenko, O. Chernyak, B. Tishkov, R. Ahmedov, SHS Web of Conferences 65, 06007 (2019)

[2] M.Z. Zghurovskyi, Stalyy rozvytok u hlobal'nomu $i$ rehional'nomu vymirakh: Analiz za danymy $2005 \mathrm{r}$. (Sustainable development in the global and regional dimensions: Analysis according to 2005) (2006)

[3] A.V. Sergienko, Ph.D. thesis, Classic Private University (2017)

[4] K. Schwab, The fourth industrial revolution (Currency, 2017)

[5] G.B. Kleiner, Economics and Mathematical Methods 3, 71 (2013)

[6] T.S. Klebanova, N.A. Kizim, Models of estimation, analysis and forecasting of socioeconomic systems (Inzhek, 2010)

[7] A. Bielinskyi, I. Khvostina, A. Mamanazarov, A. Matviychuk, S. Semerikov, O. Serdyuk, V. Solovieva, V. Soloviev, IOP Conference Series: Earth and Environmental Science 628 (2021)

[8] V.H. Pshihopov, M.Y. Medvedev, Estimation and management in complex dynamical systems (Fizmatlit, 2009)

[9] L.M. Savchuk, K.F. Kovalchuk, Economic cybernetics: modeling of socio-economic systems (Porogi, 2017)

[10] I.M. Lyashenko, Fundamentals of mathematical modeling of economic, ecological and social processes (Bogdan, 2006) 